realized that, on the administrative side, there is one factor which is most important in a good training of this kind, namely, a high proportion of 'masters' to 'apprentices'. The number of research students that one senior research worker can handle satisfactorily must obviously vary to some extent with the nature of his subject and the kind of problems he gives to his students; but it is doubtful whether in any circumstances research students can have the best possible guidance if the number of apprentices supervised by one tutor exceeds five. In some subjects the number must not be even so high as that. This means that such postgraduate training of research workers, if it is to be really good, must be expensive. But the men trained should be very valuable material which is being made into something of first-rate importance. It should therefore be worth while to spare nothing that will contribute to the making. It would be hard to conceive of any more interesting and satisfactory duty for a scientific man than the making of a research worker out of a good graduate. In order not to end on a note of pessimism, we must say nothing about the 'master's' feelings on the rare occasions when he suffers from an ill-chosen 'apprentice'. (Principal).

Imperial College of Tropical Agriculture, Trinidad.

${ }^{1}$ See NATURE, 147, 282 (1941).

\section{Behaviour of Thiuram Sulphides, etc., in Spore Germination Tests}

Some seven years ago, in the course of sorting tests of potential organic fungicides, it was noticed that tetramethylthiuram monosulphide sometimes gave

\section{O. T. FAulkner}

on the latter substance reported by Dimond et al. ${ }^{1}$, using spores of Macrosporium sarcinceforme.

We are now able to report that, far from being an isolated occurrence peculiar to the tetramethylthiuram sulphides, this property of 'inversion' of toxicity is shared by some other thiuram sulphides and some dithiocarbamates. It is probable, indeed, that it is a general property of these groups, still unnoticed in some cases because the range of concentration - often a very narrow one-within which it occurs has not yet been located. This is illustrated by the accompanying table giving qualitatively the results of a preliminary survey of some thiuram sulphides.

Only in the case of tetramethyl-and dimorpholylthiuram monosulphides was 'inversion' apparent. When, however, a more critical comparison was made with the view of obtaining quantitative data on the relation of molecular constitution to toxicity, narrower ranges of concentration were examined and 'inversion' was established in the following cases.

Tetramethylthiuram monosulphide

disulphide

Dimorpholylthiuram monosulphide

Dipentamethylenethiuram monosulphide disulphide

as well as in the case of

$$
\begin{aligned}
& \text { Sodium diethyldithiocarbamate } \\
& \text { " morpholyldithiocarbamate } \\
& \text { Zinc ," } \\
& \text { Sodium pentamethylenedithiocarbamate } \\
& \text { Piperidine ", }
\end{aligned}
$$

A variety of hypotheses could be advanced to explain this behaviour on biological, physical, or chemical grounds, but thus far little positive evidence in support of any is forthcoming. Certain considerations can, however, be put forward. The occurrence of the phenomenon in relation to two organisms as different in character as $V$. incequalis and $M$. sar. cinoforme suggests that a biological peculiarity in the response of the organism is not a probable explanation. Again, an explanation on purely physical grounds, such as changes of solubility relationships or in particle size or structure

$A$, no spores germinated ; $B$, mainly ungerminated ; $C$, many germinated ; $D$, mainly germinated on dilution, seems to be
ces cover a range from

irregular results. In certain tests an 'inversion' of toxicity occurred, that is, within a limited range of concentration, toxicity to fungus spores (Venturia inoequalis) decreased as the concentration of fungicide increased. When this effect was first observed it was ascribed to some experimental mishap, but it was repeated with sufficient frequency, though not invariably, to convince us that the phenomenon was authentic. It was later seen in the case of tetramethylthiuram disulphide, though not before several tests had been completed without any indication of it, and has been investigated most fully in relation to this compound. Confirmation of the effect has since been provided by the independent observations inadequate since the substances cover a range from
the very freely soluble to the almost insoluble, and include both the crystalline and the amorphous. It is likely, therefore, that explanation must be sought primarily in the chemical reactions of these notoriously labile substances, and experiments with this objective are now in progress. H. B. S. MonTgomery.

H. SHAw.

East Malling Research Station, East Malling,

Kent.

Feb. 22.

${ }^{2}$ Dimond, Horsfall, Heuberger and Stoddard, Conn. (New Haven) Agric. Exp. Sta. Bull. 451 (1941). 